\title{
Divergent Mating Systems and Parental Conflict as a Barrier to Hybridization in Flowering Plants
}

\section{Citation}

Brandvain, Yaniv and David Haig. 2005. Divergent mating systems and parental conflict as a barrier to hybridization in flowering plants. American Naturalist 166(3): 330-338.

\section{Published Version}

http://dx.doi.org/10.1086/432036

\section{Permanent link}

http://nrs.harvard.edu/urn-3:HUL.InstRepos:2961254

\section{Terms of Use}

This article was downloaded from Harvard University's DASH repository, and is made available under the terms and conditions applicable to Other Posted Material, as set forth at http:// nrs.harvard.edu/urn-3:HUL.InstRepos:dash.current.terms-of-use\#LAA

\section{Share Your Story}

The Harvard community has made this article openly available.

Please share how this access benefits you. Submit a story.

\section{Accessibility}




\section{Divergent Mating Systems and Parental Conflict as a Barrier to Hybridization in Flowering Plants}

\author{
Yaniv Brandvain ${ }^{1, *}$ and David Haig ${ }^{2, \dagger}$ \\ 1. College of the Atlantic, Bar Harbor, Maine 04609; \\ 2. Department of Organismic and Evolutionary Biology, Harvard \\ University, Cambridge, Massachusetts 02138 \\ Submitted October 31, 2004; Accepted April 22, 2005; \\ Electronically published June 28, 2005 \\ Online enhancement: appendix.
}

During reproduction, males and females may be in conflict over fertilization (Eberhard and Cordero 1995). After fertilization, parental conflicts continue because maternally and paternally inherited genes have different optima in relation to maternal investment in offspring (Haig 2000). These conflicts are greatest in outcrossing populations, while kin-based cooperation decreases conflict in inbred populations. Therefore, in outcrossing populations, strong paternal actions should be matched by equal maternal countermeasures. In inbreeding populations, these forces will be weaker but will be similarly balanced. Consequently, crosses between plants of different mating systems will be unbalanced, with a strong force (the outcrosser) matched by a weak counterforce (the inbreeder). We call this the weak inbreeder/strong outbreeder (WISO) hypothesis.

In relation to pollen-pistil interactions, "inbred" pollen is predicted to mount a weak challenge to strong barriers in "outbred" styles, whereas outbred pollen should easily overcome the weak barriers of inbred styles. In relation to seed development, paternally expressed genes are predicted to cause rapid proliferation of the endosperm, while maternally expressed genes should inhibit endosperm growth (Haig and Westoby 1991). The endosperm garners resources from maternal tissue and nourishes the embryo and is the triploid product of the fertilization of the two central cell nuclei of the megagametophyte. The strength of opposing parental forces is influenced by a population's mating system (Kondoh and Higashi 2000). Therefore, we predict that hybrid seeds will show symptoms of paternal excess when the pollen parent is more outbred than the seed parent and maternal excess in the reciprocal cross (symptoms of maternal and paternal excess are discussed in "Postzygotic Effects on Seed Development" below). Both cases present barriers to hybridization and can thus contribute to speciation.

In the next two sections, we explain the relevance of the WISO to pollen-pistil interactions and seed development, respectively, and present predictions of our hypothesis. Next, we summarize published information rel-

\footnotetext{
* Present address: Department of Biology, Indiana University, Bloomington, Indiana 47405; e-mail: ybrandva@indiana.edu.

† E-mail: dhaig@oeb.harvard.edu.
}

Am. Nat. 2005. Vol. 166, pp. 330-338. (C) 2005 by The University of Chicago 0003-0147/2005/16603-40718\$15.00. All rights reserved. 
evant to the WISO hypothesis. Finally, we evaluate the standing of this hypothesis.

\section{Pollen-Pistil Interactions}

In most crosses between closely related self-incompatible (SI) and self-compatible (SC) plants, SI pollen grows in SC styles, but SC pollen is inhibited in SI styles (Lewis and Crowe 1958; de Nettancourt 1977). This pattern, labeled the SI $\times$ SC rule by Murfett et al. (1996), occurs in taxa with gametophytic, sporophytic, and heteromorphic SI. In four exceptional cases, noted by Lewis and Crowe (1958), in which SC pollen grew in SI styles, SC had originated only recently from SI. Thus, unilateral incompatibility (UI) occurs in taxa with diverse SI mechanisms and appears to be a delayed response to changes in mating system. This suggests that the SI $\times$ SC rule is part of an adaptive response to changes in mating system, not a historical accident or mechanistic necessity associated with this change.

Pollen rejection in SI $\times$ SC crosses (seed parent first) is a complex, multigenic process, but the $\mathrm{S}$ locus, which is involved in SI, plays a role (Murfett et al. 1996; Bernacchi and Tanksley 1997). The relative importance of the S locus, however, is controversial (Hogenboom 1975). The observations that there are exceptions to the SI $\times$ SC rule and that the physiology, location, and timing of pollen tube arrest of UI is different than the SI reaction (Liedl et al. 1996) contribute to the controversy.

We do not wish to add to this debate, but we suggest that the WISO hypothesis provides an adaptive explanation for the SI $\times$ SC rule. In outcrossing species, pollen tubes are, for the most part, unrelated to the sporophytic tissues through which they grow and often are unrelated to the pollen tubes with which they "compete." By contrast, as self-pollination becomes more common, pollen tubes that compete for ovules approach genetic identity with each other and (except for ploidy) with the sporophytic tissues through which they grow. Thus, the potential for sexual conflicts is greatest in outcrossers, while the benefit of kin-based cooperation between pollen and style is greatest in self-fertilizers.

The WISO hypothesis explains the SI $\times$ SC rule as a reduced ability of SC pollen to overcome obstacles to fertilization present in SI styles, as these barriers are not retained in SC styles. Thus, the difference in the degree of sexual conflict in pollen-pistil interactions is the critical factor for UI (a prezygotic version of the WISO hypothesis). By this hypothesis, UI is expected in crosses between habitual outcrossers and habitual selfers when both parents are SC, transforming the SI $\times$ SC rule into a special case of a general outcrosser $\times$ inbreeder rule.

\section{Postzygotic Effects on Seed Development}

Seed development in many flowering plants depends on a correct ratio of maternal to paternal genomes (usually $2: 1$ ) in the endosperm. Disruption of this ratio leads to abnormal development (Lin 1984; Haig and Westoby 1991). Fertilization of a diploid by pollen from its own autotetraploid derivative creates endosperm with two maternal and two paternal genomes and seed characterized by paternal excess. The reciprocal cross produces endosperm with four maternal genomes and one paternal genome and seed characterized by maternal excess. In contrast, self-fertilization of autotetraploids produces endosperm with four maternal and two paternal genomes and normally developed seed.

The phenotypes of maternal and paternal excess are best characterized for species in which the endosperm undergoes free nuclear proliferation before it is cellularized. In cases of maternal excess, the number of replications before cellularization is reduced, resulting in small, plump seeds. With paternal excess, cellularization is delayed and often fails altogether, resulting in seeds that are large but "empty" (Haig and Westoby 1991). Developmental failure in crosses between some closely related diploid species resembles failure of interploidy crosses (Sansome et al. 1942; Stephens 1942; Reusch 1959a; Valentine and Woodell 1963). This resemblance has been reconciled by assigning genetic strengths to haploid genomes of different species (Nishiyama and Yabuno 1978; Johnston et al. 1980; Katsiotis et al. 1995). Nonequivalent effects of maternal and paternal genomes can be explained by the existence of imprinted genes (Haig and Westoby 1991), and imprinted expression occurs in the endosperm (Vinkenoog et al. 2003). Still, other mechanisms may explain some parentof-origin effects (Dilkes and Comai 2004; von Wangenheim and Peterson 2004). Regardless of mechanism, such differential expression allows for a manifestation of parental conflicts. Differences in levels of parental expression can act to prevent hybridization (Gutierrez-Marcos et al. 2004), contributing to reproductive isolation and, ultimately, speciation.

An imprinted gene is expressed differently in progeny depending on its parental origin. The kinship theory of genomic imprinting argues that parent-specific expression is an evolutionary response to differential selection on maternal and paternal genomes (Haig 2000). In relation to seed development, an increase in the resources acquired by one seed is associated with an opportunity cost of fewer resources available for other maternal activities, including provisioning other seeds. In self-incompatible species, seeds are often sired by multiple pollen donors. Thus, competition between paternal genomes is high, and natural selection acting on the pollen-derived genes favors 
greater acquisition of maternal resources than it does for megaspore-derived genes. By contrast, in self-fertilizing populations, a pollen tube is closely related to the pistil it traverses and to other pollen tubes growing within the pistil. Therefore, megaspore-derived and pollen-derived genes will favor similar levels of seed provisioning, with pollen-derived genes making lesser demands in inbreeding species than in outbreeding species.

The WISO hypothesis predicts that the principal factor determining genetic strength is the degree of outcrossing. As a response to reduced parental conflict, self-fertilizing species will have weaker genomes than outbreeding species. Therefore, in crosses between plants of different mating systems, there should be symptoms of maternal excess when the outcrosser is the seed parent and paternal excess in the reciprocal cross. Vrana et al. (2001) make similar predictions concerning the degree of multiple paternity and phenotypes of hybrid progeny of reciprocal crosses in mammals.

\section{Methods and Interpretation}

We undertook an extensive search of the botanical literature to evaluate the WISO hypothesis. For predictions related to seed development, the ideal study would document embryological data for reciprocal crosses between species of known mating systems. Few such studies exist. In some cases, data were only available for one direction of the cross due to UI; in other cases, seed sizes were reported, but without embryological data. Because imprinted expression is known to have a strong dosage effect, we also sought evidence from crosses that failed when both parents were diploids but succeeded when the ploidy of one parent was altered. Such crosses can provide insight into the relative genetic "strengths" of the species in question.

Crosses between outcrossers and selfers used to evaluate predictions related to seed development were also evaluated in light of prezygotic predictions of the WISO hypothesis. Throughout the text, seed parents are listed before pollen parents for consistency.

\section{Results}

\section{Lolium-Festuca Complex (Poaceae)}

Within the genus Lolium (Poaceae), crosses between selfpollinating species (Jenkin 1954c) or between outcrossing species (Jenkin 1954b) succeed. However, seed development is perturbed in crosses between self-pollinating and outcrossing species (Jenkin 1935, 1954a, 1954b). When a self-pollinating seed parent (e.g., Lolium temulentum, Lolium remotum, Lolium loliaceum) is crossed to an out- crossing species (e.g., Lolium perenne, Lolium italicum, Lolium rigidum), seeds are full length but fail to germinate. Seeds are smaller than normal, with fair germination in the reciprocal cross. Dissection of seeds from crosses between SC L. temulentum and SI L. perenne revealed large caryopses with embryos and endosperms in a slimy, decayed condition. In the reciprocal cross, the small caryopses contained a minute but well-organized endosperm (Jenkin 1935). In broad agreement with predictions of the postzygotic WISO hypothesis, these results are similar to crosses between diploid and autotetraploid L. perenne (Griffiths et al. 1971), with the inbreeder behaving as if it had a lower effective ploidy than the outcrosser. However, UI is altogether absent in Lolium, and thus the prezygotic aspect of the WISO hypothesis is not supported.

Lolium species are closely related to members of the Festuca subgenus Schedonorus (Catalán et al. 2004). Reciprocal crosses between L. perenne and Festuca pratensis exhibit differences in development resembling those observed in crosses between L. perenne and L. temulentum, with $F$. pratensis exhibiting a weaker genetic strength than L. perenne (for details, see the appendix in the online edition of the American Naturalist). Because both species are outcrossers, an interpretation in terms of mating systems is problematic. The WISO hypothesis could explain these observations if $F$. pratensis were more inbred than $L$. perenne. Both species contain individuals with significant degrees of self-fertility (Nilsson 1934), but we know of no data that allow direct comparisons of the average frequency of inbreeding in these species.

\section{Lycopersicon (Solanaceae)}

The genus Lycopersicon (tomatoes) provides an excellent opportunity for testing predictions of the WISO hypothesis because all species are diploid, and mating systems are variable both within and between species.

Pollen-Pistil Interactions. In general, crosses within the genus Lycopersicon conform to the SI $\times$ SC rule. For example, pollen from SC Lycopersicon esculentum fails to fertilize SI Lycopersicon peruvianum, while the reciprocal cross succeeds (Bohn 1948; Hogenboom 1972; de Nettancourt et al. 1974). Similarly, L. esculentum pollen does not grow in the styles of Lycopersicon [Solanum] pennellii or of Lycopersicon hirsutum, while the reciprocal crosses successfully set seed (Rick 1960; Martin 1961b, 1963, 1964; Liedl et al. 1996). Unilateral incompatibility is present whether L. esculentum is crossed to SC or SI accessions of L. pennellii or L. hirsutum. Therefore, UI in these crosses is not a simple mechanistic interaction between the pollen of an SC parent and the style of an SI parent because it 
is also present in crosses between SC L. esculentum and SC accessions of the other two species.

Martin (1961a) further examined UI within L. hirsutum by performing all possible reciprocal crosses between four accessions (two SI, two SC) of this species. The accessions could be arranged in a linear series-Chillon I (SI) > Cajamarca (SI) > Chillon II (SC) > Baños (SC)—such that pollen from accessions earlier in the series could grow in the styles of later accessions, but not the reverse. Reciprocal crosses between SI and SC accessions obeyed the SI $\times$ SC rule; however, UI was also present in SI $\times$ SI and SC $\times$ SC crosses. Martin (1963) suggested that this pattern could be explained by "postulating a variable amount of pollen-tube growth-promoting substance in pollen, complemented by an appropriate amount of an inhibiting substance in the style, which results in a controlled balance of growth substances" (p. 527).

Further examination of SC $\times$ SC L. hirsutum crosses suggests that the effectiveness of $L$. hirsutum accessions as pollen parents correlates with the degree of inbreeding in the population from which it originated: SC Baños was more selffertile than SC Chillon II (inferred from Martin 1963), and Baños pollen did not grow in Chillon II styles but Chillon II pollen grew in Baños styles (Martin 1961a). Subsequent crosses (Martin 1963) strengthen this pattern. Pollen from an accession (12486) with little inbreeding depression on selfing (suggesting frequent selfing) could not grow in styles of an accession (12492) with severe inbreeding depression on selfing (suggesting infrequent selfing); however, the reciprocal cross succeeded. These data are consistent with a hypothesis that increased inbreeding favors reduced production of growth-promoting substances in pollen and reduced production of growth-inhibiting substances in styles. These results violate the SI $\times$ SC rule but conform to the modified outcrosser $\times$ inbreeder rule of the WISO hypothesis.

Postzygotic Effects on Seed Development. Postzygotic reciprocal sterility between diploids and autotetraploids has been reported from both Lycopersicon pimpinellifolium (Cooper and Brink 1945) and L. esculentum (Bohn 1948), suggesting that effects of maternal and paternal genomes must be balanced for normal seed development in Lycopersicon. In some intraploidy crosses this balance appears to be disturbed. When diploid SC seed parents ( $L$. pimpinellifolium and L. esculentum) are pollinated by diploid SI $L$. peruvianum, ovules are fertilized but the seeds abort. By contrast, crossing autotetraploids of these SC species with diploid SI $L$. peruvianum produces viable seed (Cooper and Brink 1945; Bohn 1948; Szteyn 1965), suggesting that failure of the cross at the diploid level is due to "paternal excess." This pattern is consistent with predictions of the WISO hypothesis. Interestingly, pollen from tetra- ploid L. esculentum is inhibited in both diploid and tetraploid L. peruvianum pistils (Bohn 1948). Thus, increased ploidy can rescue seed development but does not affect the prezygotic barrier.

A difficult case for the WISO hypothesis is the cross between $L$. peruvianum var. humifusum (SI seed parent) and an SI accession of L. peruvianum. Seeds from this cross exhibit paternal excess, while seeds from the reciprocal cross exhibit maternal excess (Rick 1963; for details, see the appendix). This is a challenge for the WISO hypothesis because both parents are SI, and thus this difference does not correlate with mating system. However, variation in results depending on which accession of $L$. p. var. humifusum is used and a possible phylogenic misplacement of this group (Miller and Tanksley 1990) make interpretation difficult.

In summary, results of reciprocal crosses between SC $L$. esculentum (or L. pimpinellifolium) and SI L. peruvianum support predictions of the WISO hypothesis. However, similar differences in reciprocal crosses between $L$. peruvianum and $L$. p. var. humifusum are not readily explainable by our hypothesis.

\section{Tuber-Bearing Solanum (Solanaceae)}

Extensive interspecific crosses have been reported in Solanum section Petota (potatoes and their tuber-bearing relatives), but comparisons in this group are complicated by the existence of species at multiple ploidy levels and a confused taxonomy (van den Berg et al. 1998). We limit our discussion to a few examples that support the WISO hypothesis and one counterexample.

Reciprocal crosses between perfectly SC Solanum acaule $(2 n=4 x=48)$ and predominantly outcrossing Solanum tuberosum $(2 n=4 x=48)$ are unsuccessful. However, when Solanum acaule is the seed parent and its ploidy is doubled $(4 n=8 x=96)$, the cross is successful (Lam 1953). The anthers of $S$. acaule dehisce directly onto its stigma, and self-fertilization is probably the rule. By contrast, although S. tuberosum is SC, pollen cannot reach stigmas unless it is transferred by insects (Hawkes and Hjerting 1969).

Two significant conclusions can be drawn from these crosses. First, pollen from self-fertilizing $S$. acaule (whether $2 n$ or $4 n$ ) was inhibited in the styles of partially outcrossing S. tuberosum. Since both parents are SC, this violates the SI $\times$ SC rule but not the outcrosser $\times$ inbreeder rule. Second, S. acaule $\times S$. tuberosum failed when both parents were of equal ploidy but succeeded when $S$. acaule was tetraploid. Thus, the failure of the initial cross (with the outcrossing pollen parent) can be ascribed to paternal excess, supporting the WISO hypothesis

Manipulation of ploidy rescued additional, otherwise incompatible, Solanum crosses (Johnston and Hanneman 
1982). Self-compatible Solanum brevidens (seed parent) successfully crossed with SI Solanum chacoense, but only if the ploidy of the SC parent was doubled, supporting predictions of the WISO hypothesis. By contrast, SC Solanum verrucosum did not cross with SI Solanum cardiophyllum when both parents were diploid but succeeded when the ploidy of the SI parent was doubled, contrary to predictions of the WISO hypothesis (see Pandey [1962] for SC of S. brevidens and S. verrucosum; Lamm [1953] for SI of S. chacoense; Kuhl et al. [2002] for SI of S. cardiophyllum).

\section{Leavenworthia (Brassicaceae)}

Lloyd (1968) reported results of 14 crosses among nine populations of Leavenworthia crassa and Leavenworthia alabamica with varying degrees of self-compatibility. All crosses yielded viable seed; therefore, absolute UI was absent. However, the proportion of pollinations that produced fruit and the number of seeds per fruit declined as pollen parents became more SC than seed parents. There was no evidence of substantial numbers of aborted seeds, so these effects appeared to be prezygotic. Lloyd (1968) interpreted his results as an expression of UI, except that the failure of crosses was not absolute. This interpretation supports the prezygotic WISO hypothesis.

In support of postzygotic predictions of the WISO hypothesis, Lloyd (1968, table 4 therein) correlated relative seed weight with difference in relative SI of the parents. That is, seed parents produced smaller seeds in crosses in which they were relatively more SI than pollen parents but larger seeds when they were relatively less SI than pollen parents.

\section{Arabidopsis (Brassicaceae)}

Unlike interploidy crosses in most species, crosses between diploid and autotetraploid Arabidopsis thaliana yield viable seed in both directions. Seed size is increased when the pollen parent is tetraploid but is decreased in the reciprocal cross. This result is consistent with a growth-enhancing role of paternal genomes and a growth-inhibitory role of maternal genomes. The unusual viability of the offspring of interploidy crosses in A. thaliana has been ascribed to reduced parental conflict in this predominantly selffertilizing species (Scott et al. 1998).

Arabidopsis thaliana $(2 n=2 x=10)$ is SC and diploid, while Arabidopsis arenosa $(2 n=4 x=32)$ is SI and tetraploid. In the cross between $A$. arenosa (seed parent) and A. thaliana, pollen failed to germinate, but pollen germinated and successfully fertilized ovules in the reciprocal cross (Bushell et al. 2003), providing an example of the SI $\times$ SC rule. Resultant seeds exhibited symptoms of pa- ternal excess. However, these results cannot be unambiguously ascribed to differences in mating system because a difference in ploidy confounds this observation.

Bushell et al. (2003) circumvented this difficulty by crossing autotetraploid A. thaliana (seed parent) with $A$. arenosa. Some seeds from this cross were viable but exhibited delayed cellularization of the endosperm, indicating a paternalizing effect of the outcrossing pollen parent. The hybrids obtained from this cross, $2 n=4 x=26$, have been called synthetic A. suecica (SAS) and can be successfully crossed to A. thaliana bidirectionally.

Reciprocal crosses between SAS and autotetraploid $A$. thaliana have been interpreted as indicating that SAS has a higher genetic strength than $A$. thaliana (Bushell et al. 2003). A reanalysis of the data, however, provides only equivocal support for this interpretation (see appendix for details). The dominant effect in these crosses appears to be that an $A$. arenosa genome increases seed weight and number of endosperm nuclei independent of parental origin; however, there is some evidence for parent-of-origin effects. Thus, results from Arabidopsis crosses cannot be clearly interpreted in relation to the WISO hypothesis.

\section{Other Groups}

Here we discuss crosses that produce seed with symptoms of maternal and paternal excess but that lack obvious differences in mating systems.

All Gossypium species (Malvaceae) are SC, but many have showy flowers that attract insect pollinators (e.g., Wendel et al. 1991). The cultivated tree cotton of India Gossypium arboreum $(2 n=2 x=26)$ produces empty seeds when pollinated by the wild diploid species Gossypium aridum, Gossypium armourianum, and Gossypium raimondii (Stephens 1942). However, these crosses produce normal seed when autotetraploid G. arboreum $(4 n=4 x=52)$ is the seed parent. Stephens concluded that failure of the cross using diploid G. arboreum was due to an imbalance between parental genomes, with G. arboreum having a weaker genome than the wild diploids. These conclusions would support the WISO hypothesis if outcrossing is more common in wild diploids. The anthers of G. arboreum are found in direct contact with the stigma, and they shed pollen as soon as the flower opens (Kottur 1921); its natural rate of outcrossing is about 2\% (Afzal and Khan 1950). Thus, G. arboreum is predominantly self-fertilized. We have found no comparable data on the mating systems of the wild species.

Nishiyama and Yabuno $(1978,1983)$ assigned activating values (AVs) to Avena species that are qualitatively equivalent to genetic strength (Avena strigosa is assigned the reference value 1.0). Among diploids, AVs range from 0.4 (Avena ventricosa) to 1.7 (Avena longiglumis). All Avena 
Table 1: Evidence relating to the prezygotic WISO hypothesis

\begin{tabular}{lcc}
\hline Taxon & Support & Notes \\
\hline Arabidopsis & + & The SI $\times$ SC rule holds. \\
Leavenworthia & + & UI is absent, but fertilization is more successful when pollen donors are \\
more SI than seed parents. \\
Lolium & 0 & There is interspecific variation in mating systems but no UI. \\
Lycopersicon & + & The SI $\times$ SC rule holds for crosses between mating systems. \\
& + & When UI is present in crosses within mating systems, the more inbred \\
Tuber-bearing Solanum & + & Thoup behaves like a selfer. \\
& + & UI occurs in directions predicted by the WISO hypothesis in Solanum acaule \\
& & (SC selfing) $\times$ Solanum tuberosum (SC outcrossing) crosses.
\end{tabular}

Note: Summary of evidence relating to the WISO (weak inbreeder/strong outbreeder) hypothesis. When specific crosses are discussed in the Notes column, seed parents are listed first. $+=$ supportive, $0=$ inconclusive, SI $=$ self-incompatility, SC $=$ self-compatibility, $\mathrm{UI}=$ unilateral incompatibility.

species are SC. The WISO hypothesis predicts that AVs increase with the frequency of outcrossing. Avena ventricosa appears to be predominantly self-pollinating (Rajhathy 1971). Thus, substantial outcrossing in A. strigosa, and especially A. longiglumis, would support the WISO hypothesis. No evidence directly addresses this issue; however, A. longiglumis has giant anthers (Nishiyama and Yabuno 1975), suggesting that pollen is transferred to nonself stigmas.

Crosses between Primula elatior (seed parent) and Primula veris produced large empty seeds (labeled type $\mathrm{B}$ ). The reciprocal cross produced small seeds (labeled type A). Type B seeds were also observed when P. veris or P. elatior were pollinated by their own autotetraploids, whereas type A seeds were observed in the reciprocal crosses (Valentine and Woodell 1963). These results cannot readily be ascribed to differences in mating systems because both species exhibit heteromorphic SI.

\section{Discussion}

We suggest that changes in mating system will change levels of sexual conflict and that changes in levels of conflict will result in genetic incompatibilities between populations, contributing to incipient speciation. Strong levels of conflict exist in populations with a high degree of outcrossing to multiple partners, and a change to a high degree of selffertilization will decrease conflict. In crosses between plants of different mating systems, genetic incompatibilities can be viewed as a consequence of outcrossing genomes overpowering selfing genomes, preventing normal fertilization and development.

\section{Pollen-Pistil Interactions}

We have shown that the SI $\times$ SC rule is a useful generalization-with some exceptions. Even as they promul- gated the rule, Lewis and Crowe (1958) noted some exceptions, and many further exceptions have been noted since. Here we place the SI $\times$ SC rule in a theoretical context of the WISO hypothesis and explain some exceptions (table 1 summarizes prezygotic data). We interpret the SI $\times$ SC rule as an expression of differing degrees of parental conflict in species with different mating systems.

Our review highlights crosses in which the direction of UI was predicted by differences in the degree of outbreeding even though neither parent was SI (e.g., Leavenworthia races and Lycopersicon hirstutum accessions). These examples suggest that UI is not merely a direct mechanistic consequence of the breakdown of self-incompatibility but reflects some difference in underlying selective forces. The occurrence of SI $\times$ SC unilateral incompatibility in taxa with diverse mechanisms of SI supports this conclusion.

\section{Postzygotic Effects on Seed Development}

Many, but not all, crosses discussed support predictions of the postzygotic WISO hypothesis (table 2). On the other hand, crosses between Arabidopsis species provide only equivocal support for the WISO hypothesis. The clearest violation of the WISO hypothesis occurs in crosses between Solanum cardiophyllum and Solanum verrucosum, which succeeds when the WISO hypothesis predicts it to fail and fails when the WISO hypothesis predicts it to succeed.

Some crosses produce seed with symptoms of maternal or paternal excess but appear to have similar mating systems. Such results would support the WISO hypothesis if these groups contain cryptic variation in mating systems. Alternatively, other factors could determine levels of differential expression (i.e., differences in cost of the expression of imprinted genes; see Kondoh and Higashi 2000).

Differences in levels of imprinting may promote spe- 
Table 2: Evidence relating to the postzygotic WISO hypothesis

\begin{tabular}{|c|c|c|}
\hline Taxon & Support & Notes \\
\hline Arabidopsis & 0 & Outcrossing genomes increase seed size regardless of parental origin. \\
\hline \multicolumn{3}{|l|}{ Avena, Primula, and } \\
\hline Gossypium & 0 & Genetic strengths vary, but mating systems do not. \\
\hline Leavenworthia & + & Seeds are less massive when seed parents are more SI than the pollen parents. \\
\hline \multirow[t]{2}{*}{ Lollium-Festuca } & + & Outcrossing genomes are "stronger" than selfing ones. \\
\hline & 0 & $\begin{array}{l}\text { Lollium pernne and Festuca pratensis have different "strengths," but both are } \\
\text { outcrossers. }\end{array}$ \\
\hline \multirow[t]{2}{*}{ Lycopersicon } & + & $\begin{array}{l}\text { Lycopersicon esclentum (seed parent, SC) } \times \text { Lycopersicon peruvianum or Lyco- } \\
\text { persicon pimpinellifolium (both SI) succeeds when L. esclentum is tetraploid. }\end{array}$ \\
\hline & 0 & L. peruvianum (SI) is "stronger" than (SI) L. peruvianum var. humifusum. \\
\hline \multirow[t]{3}{*}{ Tuber-bearing Solanum } & + & $\begin{array}{l}\text { Solanum acaule pollinated by outcrossing Solanum tuberosum develops nor- } \\
\text { mally when } S \text {. acuale is tetraploid. }\end{array}$ \\
\hline & + & $\begin{array}{l}\text { Solanum brevidens (SC) pollinated by Solanum chacoense (SI) develops nor- } \\
\text { mally when S. brevidens is tetraploid. }\end{array}$ \\
\hline & - & $\begin{array}{l}\text { Solanum verrucosum }(\mathrm{SC}) \times \text { Solanum cardiophyllum }(\mathrm{SI}) \text { succeeds when the } \\
\text { ploidy of } S \text {. cardiophyllum is doubled. }\end{array}$ \\
\hline
\end{tabular}

Note: Summary of evidence relating to the WISO (weak inbreeder/strong outbreeder) hypothesis. When specific crosses are discussed in the Notes column, seed parents are listed first. $0=$ inconclusive, $+=$ supportive, $-=$ contradictory, SI $=$ self-incompatility, SC $=$ selfcompatibility.

ciation (Gutierrez-Marcos et al. 2004). Thus, the WISO hypothesis suggests that processes involved in parental conflict (i.e., genomic imprinting) can act as reproductive isolating mechanisms in plants. This prediction is similar to that of Zeh and Zeh (2000), which suggests that parental conflict can lead to speciation in viviparous animals.

\section{Conclusion}

When two groups become reproductively isolated, genes from one population are no longer regular partners of genes from the other population. Therefore, genetic incongruities can accumulate between the two gene pools, perturbing development in subsequent crosses. It would be naive to expect that one simple hypothesis should explain all genetic incongruities. Thus, the WISO hypothesis, like the SI $\times$ SC rule, will ultimately be judged on whether it explains a significant proportion of incongruities rather than being rejected by a single counterexample. If the WISO hypothesis is important for speciation, a possible consequence (not addressed here) is that time from divergence to speciation will be shortened when one population experiences a shift in its mating system.

We have focused on the implications of changes of mating system for the origin of incongruities in plant hybrids; however, similar effects are predicted in other groups. During mammalian development, imprinted genes tend to promote growth when paternally expressed but suppress growth when maternally expressed (Tycko and Morison 2002). Haig and Graham (1991) explained this pattern as a consequence of paternally derived genes favoring higher levels of fetal growth than maternally derived genes because mothers have offspring by multiple fathers (Haig and Graham 1991). A corollary of this hypothesis is that as multiple mating by females decreases, so should parental conflict. Dawson (1965) noted that when the primarily monogamous old field mouse Peromyscus polionotus fathered pups by the polygamous deer mouse Peromyscus maniculatus, pups were smaller than normal, whereas pups were larger than normal in the reciprocal cross. This is consistent with a lesser intensity of parental conflict in Peromyscus polionotus. Vrana et al. (2001) showed that imprinted genes contribute to the size difference in these crosses.

Because previously published data were originally collected for other purposes, they are not ideal for hypothesis testing. Embryological data collected from multiple species pairs explicitly for testing this hypothesis will allow for stronger conclusions. The large number of independent origins of self-fertilization and the relative ease of plant hybridization make the prospects for testing the contribution of changes in mating system to the origin of postzygotic incongruities between species particularly promising in plants.

\section{Acknowledgments}

I. Anderson, I. Brandvain, J. Busch, L. Delph, J. Demuth, S. Morse, C. Petersen, N. Rajakaruna, S. Salinas, and D. Wolf provided insightful comments. L. Fishman, L. Moyle, and D. Wolf provided guidance. C. Greene provided inspiration. 


\section{Literature Cited}

Afzal, M., and H. Khan. 1950. Natural crossing in cotton in Western Punjab. Agronomy Journal 42:14-19, 89-93, 202-205, 236-238.

Bernacchi, D., and S. D. Tanksley. 1997. An interspecific backcross of Lycopersicon esculentum $\times$ L. hirsutum: linkage analysis and a QTL study of sexual compatibility factors and floral traits. Genetics 147:861-877.

Bohn, G. W. 1948. Sesquidiploid $\mathrm{F}^{1}$ hybrids of Lycopersicon esculentum and L. peruvianum. Journal of Agricultural Research 77:33-53.

Bushell C., M. Spielman, and R. J. Scott. 2003. The basis of natural and artificial postzygotic hybridization barriers in Arabidopsis species. Plant Cell 15:1430-1442.

Catalán P., P. Torrecilla, J. A. L. Rodriguez, and R. G. Olmstead. 2004. Phylogeny of the festucoid grasses of subtribe Loliinae and allies (Poeae, Pooideae) inferred from ITS and trnL-F sequences. Molecular Phylogenetics and Evolution 31:517-541.

Cooper, D. C., and R. A. Brink. 1945. Seed collapse following matings between diploid and tetraploid races of Lycopersicon pimpinellifolium. Genetics 30:376-401.

Dawson, W. D. 1965. Fertility and size inheritance in a Peromyscus species cross. Evolution 19:44-55.

de Nettancourt, D. 1977. Incompatibility in angiosperms. Springer, Heidelberg.

de Nettancourt, D., M. Devreux, U. Laneri, M. Cresti, E. Pacini, and G. Sarfatti. 1974. Genetical and ultrastructural aspects of self and cross incompatibility in interspecific hybrids between selfcompatible Lycopersicon esculentum and self-incompatible L. peruvianum. Theoretical and Applied Genetics 44:278-288.

Dilkes, B. P., and L. Comai. 2004. A differential dosage hypothesis for parental effects in seed development. Plant Cell 16:3174-3180.

Griffiths, D. J., R. A. D. Pegler, and T. Tonguthaisri. 1971. Cross compatibility between diploid and tetraploid perennial ryegrass (Lolium perenne L.). Euphytica 20:102-112.

Gutierrez-Marcos, J. F., P. D. Pennington, L. M. Costa, and H. G. Dickinson. 2004. Imprinting in the endosperm: a possible role in preventing wide hybridization. Philosophical Transactions of the Royal Society of London B 358:1105-1111.

Eberhard, W. G., and C. Cordero. 1995. Sexual selection by cryptic female choice on male seminal products: a new bridge between sexual selection and reproductive physiology. Trends in Ecology \& Evolution 10:493-496.

Haig, D. 2000. The kinship theory of genomic imprinting. Annual Review of Ecology and Systematics 31:9-32.

Haig, D., and C. Graham. 1991. Genomic imprinting and the strange case of the insulin-like growth factor-II receptor. Cell 64:10451046.

Haig, D., and M. Westoby. 1991. Genomic imprinting in the endosperm: its effects on seed development in crosses between species and between different ploidies of the same species, and its implications for the evolution of apomixis. Philosophical Transactions of the Royal Society of London B 333:1-13.

Hawkes, J. G., and J. P. Hjerting. 1969. The potatoes of Argentina, Brazil, Paraguay, and Uruguay: a biosystematic study. Oxford University Press, Oxford.

Hogenboom, N. G. 1972. Breaking breeding barriers in Lycopersicon. V. The inheritance of the unilateral incompatibility between $L$. peruvianum (L.) Mill. and L. esculentum Mill. and the genetics of its breakdown. Euphytica 21:405-414.

1975. Incompatibility and incongruity: two different mech- anisms for the non-functioning of intimate partner relationships. Proceedings of the Royal Society of London B 188:361-374.

Jenkin, T. J. 1935. Interspecific and intergeneric hybrids in herbage grasses. II. Lolium perenne $\times$ L. temulentum. Journal of Genetics 31:379-412.

1954a. Interspecific and intergeneric hybrids in herbage grasses. V. Lolium rigidum sens. ampl. with other Lolium species. Journal of Genetics 52:252-281.

1954b. Interspecific and intergeneric hybrids in herbage grasses. VI. Lolium italicum intercrossed with other Lolium types. Journal of Genetics 52:282-299.

1954c. Interspecific and intergeneric hybrids in herbage grasses. VIII. Lolium loliaceum, Lolium remotum and Lolium temulentum, with references to 'Lolium canadense'. Journal of Genetics 52:318-331.

Johnston, S. A., and R. E. Hanneman. 1982. Manipulations of endosperm balance number overcome crossing barriers between diploid Solanum species. Science 217:446-448.

Johnston, S. A., T. P. M. den Nijs, S. J. Peloquin, and R. E. Hanneman Jr. 1980. The significance of genic balance to endosperm development in interspecific crosses. Theoretical and Applied Genetics 57:5-9.

Katsiotis, A., R. E. Hanneman Jr., and R. A. Forsberg. 1995. Endosperm balance number and the polar-nuclei activation hypotheses for endosperm development in interspecific crosses of Solanaceae and Gramineae, respectively. Theoretical and Applied Genetics 91: 848-855.

Kondoh, M., and M. Higashi. 2000. Reproductive isolation mechanism resulting from resolution of intragenomic conflict. American Naturalist 156:511-518.

Kottur, G. L. 1921. Cross-fertilization and sterility in cotton. Agricultural Journal of India 16:52-59.

Kuhl, J. C., M. J. Havey, and R. E. Hannemann. 2002. A genetic study of unilateral incompatibility between diploid (1EBN) Mexican species Solanum pinnatisectum and S. cardiophyllum subsp. cardiophyllum. Sexual Plant Reproduction 14:305-313.

Lamm, R. 1953. Investigations on some tuber-bearing Solanum hybrids. Hereditas 39:97-112.

Lewis, D., and L. K. Crowe. 1958. Unilateral incompatibility in flowering plants. Heredity 12:233-256.

Liedl, B. E., S. McCormick, and M. A. Mutschler. 1996. Unilateral incongruity in crosses involving Lycopersicon pennellii and L. esculentum is distinct from self-incompatibility in expression, timing and location. Sexual Plant Reproduction 9:299-308.

Lin, B.-Y. 1984. Ploidy barrier to endosperm development in maize. Genetics 107:103- 115.

Lloyd, D. G. 1968. Partial unilateral incompatibility in Leavenworthia (Cruciferae). Evolution 22:382-393.

Martin, F. W. 1961a. Complex unilateral hybridization in Lycopersicon hirsutum. Proceedings of the National Academy of Sciences of the USA 47:855-857.

. $1961 b$. Unilateral interspecific incompatibility in flowering plants. Heredity 12:233-256.

. 1963. Distribution and interrelationships of incompatibility barriers in the Lycopersicon hirsutum Humb. and Bonpl. complex. Evolution 17:519-528.

- 1964. The inheritance of unilateral incompatibility in $L y$ copersicon hirsutum. Genetics 50:459-469.

Miller, J. C., and S. D. Tanksley. 1990. RFLP analysis of phylogenetic 
relationships and genetic variation in the genus Lycopersicon. Theoretical and Applied Genetics 80:437-448.

Murfett J., T. J. Strabala, D. M. Zurek, B. Q. Mou, B. Beecher, and B. A. McClure. 1996. S RNase and interspecific pollen rejection in the genus Nicotiana: multiple pollen-rejection pathways contribute to unilateral incompatibility between self-incompatible and self-compatible species. Plant Cell 8:943-958.

Nilsson, F. 1934. Studies in fertility and inbreeding in some herbage grasses. Hereditas 19:1-162.

Nishiyama, I., and T. Yabuno. 1975. Meiotic chromosome pairing in two interspecific hybrids and a criticism of the evolutionary relationship of diploid Avena. Japanese Journal of Genetics 50:443451 .

. 1978. Causal relationships between polar nuclei in double fertilization and interspecific cross-incompatibility in Avena. Cytologia 43:453-466.

. 1983. A mechanism of the alteration of crossability in artificial Avena polyploids. Japanese Journal of Genetics 58:51-57.

Pandey, K. K. 1962. Interspecific incompatibility in Solanum species. American Journal of Botany 49:874-882.

Rajhathy, T. 1971. Chromosome polymorphism in Avena ventricosa. Chromosoma 35:206-216.

Reusch, J. D. H. 1959. Embryological studies on seed development in reciprocal crosses between Lolium perenne and Festuca pratensis. South African Journal of Agricultural Science 2:429-443.

Rick, C. M. 1960. Hybridization between Lycopersicon esculentum and Solanum pennellii: phylogenetic and cytogenetic significance. Proceedings of the National Academy of Sciences of the USA 46:7882.

1963. Barriers to interbreeding in Lycopersicon peruvianum. Evolution 17:216-232.

Sansome, E. R., S. Satina, and A. F. Blakeslee. 1942. Disintegration of ovules in tetraploid-diploid and in incompatible species crosses in Datura. Bulletin of the Torrey Botanical Club 69:405-420.

Scott, R. J., M. Speilman, J. Bailey, and H. G. Dickinson. 1998. Parent of origin effects on seed development in Arabidopsis thaliana. Development 125:3329-3341.
Stephens, S. G. 1942. Colchicine-produced polyploids in Gossypium. I. An autotetraploid Asiatic cotton and certain of its hybrids with wild diploid species. Journal of Genetics 44:272- 295.

Szteyn, K. 1965. Interspecific crosses in genus Lycopersicum. II. Advantage of using tetraploid tomatoes as pistillate parents in interspecific crosses. Euphytica 14:209-216.

Tycko, B., and I. M. Morison. 2002. Physiological functions of imprinted genes. Journal of Cellular Physiology 192:245-258.

Valentine, D. H., and S. R. J. Woodell. 1963. Studies in British primulas. X. Seed incompatibility in intraspecific and interspecific crosses at diploid and tetraploid levels. New Phytologist 62:125143.

van den Berg, R. G., J. T. Miller, M. L. Ugarte, J. P. Kardolus, J. Villand, J. Nienhuis, and D. M. Spooner. 1998. Collapse of morphological species in the wild potato Solanum brevicaule complex (Solanaceae: sect. Petota). American Journal of Botany 85:92-109.

Vinkenoog, R., C. Bushell, M. Spielman, S. Adams, H. G. Dickinson, and R. J. Scott. 2003. Genomic imprinting and endosperm development in flowering plants. Molecular Biotechnology 25:149184.

von Wangenheim, K.-H., and H.-P. Peterson. 2004. Aberrant endosperm development in interploidy crosses reveals a timer of differentiation. Developmental Biology 270:277-289.

Vrana, P. B., P. G. Matteson, J. V. Schmidt, R. S. Ingram, A. Joyce, K. L. Prince, M. J. Dewey, and S. M. Tilghman. 2001. Genomic imprinting of placental lactogen gene in Peromyscus. Development Genes and Evolution 211:523-532.

Wendel, J. F., J. M. Stewart, and J. H. Rettig. 1991. Molecular evidence for homoploid reticulate evolution among Australian species of Gossypium. Evolution 45:694-711.

Zeh, D. W., and J. A. Zeh. 2000. Reproductive mode and speciation: the viviparity-driven conflict hypothesis. BioEssays 22:938-946.

Associate Editor: Bernard J. Crespi Editor: Michael C. Whitlock 